\title{
Article \\ Comparative Study of Pore Structure Characteristics between Mudstone and Coal under Different Particle Size Conditions
}

\author{
Jianguo Zhang ${ }^{1}$, Xiyuan $\mathrm{Li}^{1}{ }^{\text {, Jihong Jiao }}{ }^{1}$, Jianbao Liu ${ }^{2,3}$, Feng Chen ${ }^{2, *}$ and Zhimin Song ${ }^{2, *}$ \\ 1 State Key Laboratory of Coking Coal Exploitation and Comprehensive Utilization, \\ Pingdingshan 467000, China; 2787361@163.com (J.Z.); 27241431xy@163.com (X.L.); jjhwk@sina.com (J.J.) \\ 2 School of Environmental and Biological Engineering, Henan University of Engineering, No. 1, Xianghe Road, \\ Zhengzhou 451191, China; liujianbao342@126.com \\ 3 School of Resources and Environment, Henan Polytechnic University, Jiaozuo 454000, China \\ * Correspondence: chenfeng871588@163.com (F.C.); songzhimin1961@hotmail.com (Z.S.); \\ Tel.: +86-037-1625-082-18 (F.C. \& Z.S.)
}

Citation: Zhang, J.; Li, X.; Jiao, J.; Liu, J.; Chen, F.; Song, Z. Comparative Study of Pore Structure

Characteristics between Mudstone and Coal under Different Particle Size Conditions. Energies 2021, 14, 8435. https://doi.org/10.3390/en14248435

Academic Editor: Islam Md Rizwanul Fattah

Received: 10 November 2021

Accepted: 1 December 2021

Published: 14 December 2021

Publisher's Note: MDPI stays neutral with regard to jurisdictional claims in published maps and institutional affiliations.

Copyright: (c) 2021 by the authors. Licensee MDPI, Basel, Switzerland. This article is an open access article distributed under the terms and conditions of the Creative Commons Attribution (CC BY) license (https:// creativecommons.org/licenses/by/ $4.0 /)$.

\begin{abstract}
In order to investigate the difference of pore structure characteristics between mudstone and coal under different particle size conditions, samples acquired from Henan province were smashed and screened into three different particle sizes (20-40, 80-100, and >200 mesh) to conduct the experiments, using the high-pressure mercury intrusion porosimetry (MIP) and low-temperature $\mathrm{N}_{2}$ adsorption (LT- $\mathrm{N}_{2} \mathrm{~A}$ ) techniques. The results demonstrated that the proportion of open pores or semi-enclosed pores increased, and the pores became preferable contacted each other for both mudstone and coal during the crushing process. These variations of pore structure characteristics in the coal were beneficial to methane storage and migration. The total specific surface areas and pore volumes all showed a tendency of increasing continually for both mudstone and coal, as the particle sizes decreased from the LT- $\mathrm{N}_{2} \mathrm{~A}$ test. The mudstone and coal were non-rigid aggregates with micropores, plate-shaped pores, and slit-shaped pores developed inside. The effect of the crushing process on the pore shape for the mudstone and coal was inappreciable. Moreover, the influence of the particle sizes on the mesopore was the most significant, followed by the macropore; and on the micropore, the influence was negligible for both mudstone and coal. The crushing process only had a significant impact on the pore structure of mudstone with a particle size of less than 100 mesh, while it could still alter the pore structure of coal with a particle size of larger than 100 mesh. It is believed that this work has a significant meaning to explore the diffusion and migration rules of coal-bed methane in coal.
\end{abstract}

Keywords: coal; mudstone; pore structure characteristics; mercury intrusion porosimetry measurement; low-temperature $\mathrm{N}_{2}$ adsorption

\section{Introduction}

Coal is a structurally and chemically heterogeneous organic rock with a complicated dual-porosity structure [1,2]. Coal's pores and fissures are not merely the primary storage sites for coal-bed methane (CBM), but also provide the channels for methane desorption, diffusion, and seepage $[3,4]$. Therefore, the research about coal's pore and fissure structure characteristics has important practical significance for the CBM exploitation and utilization, the disaster and prevention of methane, and the improvement of domestic air quality $[5,6]$. Various analysis technologies have been applied for characterizing the pore and fissure structure of coal, mainly including (1) the fluid penetration and gas adsorption method, such as high-pressure mercury intrusion porosimetry (MIP) [7], low-temperature $\mathrm{N}_{2}$ adsorption (LT- $\mathrm{N}_{2} \mathrm{~A}$ ), and low-pressure $\mathrm{CO}_{2}$ adsorption ( $\mathrm{LP}-\mathrm{CO}_{2} \mathrm{~A}$ ) [8]; (2) the microscopic observation method, such as visual observation (indoor coal core description and underground coal wall observation) [9,10], optical microscopy (OM) [11], field emission 
scanning electron microscopy (FESEM) [12], high-resolution transmission electron microscopy (HRTEM) [13], atomic force microscopy (AFM) [14], focused ion-beam-scanning electron microscopy (FIB-SEM) [15], etc.; (3) the radiographic detection method, such as X-ray computed microtomography technology (X-ray CT) [16], ${ }^{13} \mathrm{C}$ nuclear magnetic resonance spectroscopy $\left({ }^{13} \mathrm{C}\right.$ NMR) $[17,18]$, small angle neutron scattering (SANS) $[19,20]$, small angle X-ray scattering (SAXS) [21,22], micro-resistivity imaging logging (MIL) [9], and so on. Amongst them, the MIP, LT-N $2 \mathrm{~A}$, and $\mathrm{LP}-\mathrm{CO}_{2} \mathrm{~A}$ are the most widely applied approaches for evaluating the coal's pore and fissure structure due to owning the advantages of low cost and simple operation [23].

The literature research demonstrates that the pore-and-fissure structure of coal is affected by various parameters, including coal rank, the degree of coal deformation, coal maceral composition, mineral matter content in coal, the particle size of coal, and temperature $[4,12,24-26]$. Lately, some progress has been made about the influence of the particle size on the coal's pore/fissure structure. For example, Cheng et al. demonstrated that the pore volume and specific surface area of coal were negatively correlated with the reducing particle size, using the LT- $\mathrm{N}_{2}$ A method, which might ascribe to that the crushing process opened inaccessible and closed pores. Moreover, they found that the optimal adsorption equilibrium time for the LT- $\mathrm{N}_{2} \mathrm{~A}$ test was $8 \mathrm{~min}$ [26]. Chen's group verified that decreasing the particle size of coal leads to a consecutive increase in mesopore- and macropore-specific surface areas and volumes for the pulverized anthracite subsamples, and the closed pores' contribution to the total pore volume was 94.94\% [11]. Wang's team concluded that mesopore specific surface area and volume were highly correlated with particle size, while micropore features were not correlated with particle size for low volatile bituminous coals, using the LT- $\mathrm{N}_{2} \mathrm{~A}$ and LP-CO $\mathrm{CO}_{2} \mathrm{~A}$ experiments [8]. Because of the composition differences between the mudstone and coal, their pore characteristics, such as the pore specific surface area, pore volume, pore size distribution, pore shape, and pore connectivity, might show a difference. However, few studies have discussed in detail the difference of pore structure characteristics between mudstone and coal under different particle size conditions through the MIP and LT- $\mathrm{N}_{2} \mathrm{~A}$ measurements.

Herein, the mudstone and coal samples acquired from Pingdingshan coal mine in Henan province, Central China, were smashed and screened into three different particle sizes (20-40, 80-100, and $>200$ mesh). The information about the variations in pore structure characteristics between mudstone and coal subsamples with varying particle sizes was systematically analyzed by the MIP and LT- $\mathrm{N}_{2}$ A measurements. The pore variables test mainly included specific surface areas and volumes of macro-, meso-, and micropores, as well as pore size distribution. Moreover, the pore geometric textures, such as pore shape, porosity, and pore connectivity, were also concluded via the analysis of the hysteresis loops of the MIP and LT- $\mathrm{N}_{2}$ A testes. This study can offer a valuable reference for exploring the diffusion and migration rules of CBM in coal, which has paramount practical significance for guiding the coal mine and gas outburst and evaluating CBM reserves and exploitation.

\section{Materials and Methods}

\subsection{Chemicals and Instruments}

The deionized water (electrical conductivity: $0.1-1 \mu \mathrm{s} / \mathrm{cm}$ ), standard sieves (GB/T 6003.1-2012, Shaoxing Shangyu Huafeng Hardware Co., Ltd., Shaoxing, China), vacuumdrying chamber (DZ-2AIV, Tianjin Tester Instrument Co., Ltd., Tianjin, China), automatic mercury injection apparatus (Auto Pore Iv 9510, Norcross, GA, USA), and automatic surface area and porosity analyzer (Micromeritics ASAP 2460, Norcross, GA, USA).

\subsection{The Preparation of Mudstone and Coal Samples}

The mudstone and coal specimens were taken from the No. 2 mine of the Pingdingshan coal mine in Henan province, Central China. The coal belongs to fat coal. To minimize the innate differences of physical and chemical structures in mudstone or coal samples, the mudstone or coal samples were all collected from the adjacent area of the same coal 
floor or coal seam at the coal-mining face. The obtained samples were sealed in resealable bags to prevent oxidization by air, and then they were immediately transported to the laboratory for further experiments. The original mudstone and coal samples were smashed and sieved into three distinct particle diameters, using standard sieves (20-40, 80-100, and $>200$ mesh), and the resulting six mudstone and coal samples were labeled as A1, A2, A3, B1, B2, and B3, respectively.

\subsection{Experimental Methods}

The MIP measurement was conducted by using a mercury injection apparatus. The maximum pressure of the device was $228 \mathrm{Mpa}(33,000 \mathrm{lb})$, and the measurement range of the aperture was $5-1 \times 10^{6} \mathrm{~nm}$. The mercury injection pressure in this work was from 0.1 to $60,000 \mathrm{~Pa}$, and the volumetric veracity of mercury intrusion and extrusion was short of $0.1 \mu \mathrm{L}$. Prior to the test, the samples should be dried to the constant weight at $105{ }^{\circ} \mathrm{C}$. The LT- $\mathrm{N}_{2}$ A measurement was carried out by using a surface-area and porosity analyzer. Before the analysis, the samples were placed in a vacuum drying chamber and heated at $110{ }^{\circ} \mathrm{C}$ for eight hours to get rid of the surface water or other impurities. After the pretreatment of mudstone and coal samples, the LT- $\mathrm{N}_{2} \mathrm{~A}$ measurement was conducted. The $\mathrm{N}_{2}$ adsorption and desorption isotherms were acquired in the relative pressure $\left(\mathrm{P} / \mathrm{P}_{0}\right)$ range between 0.01 and 0.99 . Based on the adsorption branch of isotherms, the specific surface areas, pore volumes, and pore size distribution of the mudstone and coal specimens were analyzed by using the Barrett-Joyner-Halenda (BJH) theory.

At present, there are two commonly used classification schemes about the pores and fissures in the porous material: the decimal aperture classification system suggested by B. B. ХОДОТ аnd the scheme suggested by the International Union of Pure and Applied Chemistry (IUPAC) $[27,28]$. The IUPAC pore standards were followed in this work: macropore $(>50 \mathrm{~nm})$, mesopore $(2-50 \mathrm{~nm})$, and micropore $(<2 \mathrm{~nm})$.

\section{Results and Discussion}

\subsection{The MIP Measurement}

The MIP intrusive and extrusive profiles of the mudstone and coal specimens under distinct particle size conditions are displayed in Figure 1. We can see that both the mudstone and coal samples showed similar MIP shapes. However, the specific parameters, such as the cumulative intrusion volume of mercury, the mercury withdrawal efficiency, and the hysteresis cycles' degrees, were disparate for the mudstone and coal specimens with diverse particle diameters. The mercury's cumulative intrusion volume for mudstone specimens increased gradually with the decreasing particle sizes. Nevertheless, the cumulative intrusion volume of mercury in the coal sample was highest when the particle size was 80-100 mesh. This diverse phenomenon might be due to the different formation reasons of mudstone and coal, and coal mainly contained organic materials, while mudstone mainly contained inorganic materials [8,29]. Moreover, it is observed that the mercury withdrawal efficiency gradually decreased as the particle sizes decreased for all the samples, thus indicating that the isolated massive pore clusters occurred in the continuous tiny pore networks in the samples with small particle sizes. In such aperture systems, mercury was primitively drawn from tiny apertures as pressure declined. With the further reduction of pressure for extruding mercury from the huge apertures, the tiny pore throat channels were fragmented by mercury, and a large amount of mercury remained in the huge isolated pores, leading to a low mercury-extrusion efficiency $[30,31]$. 

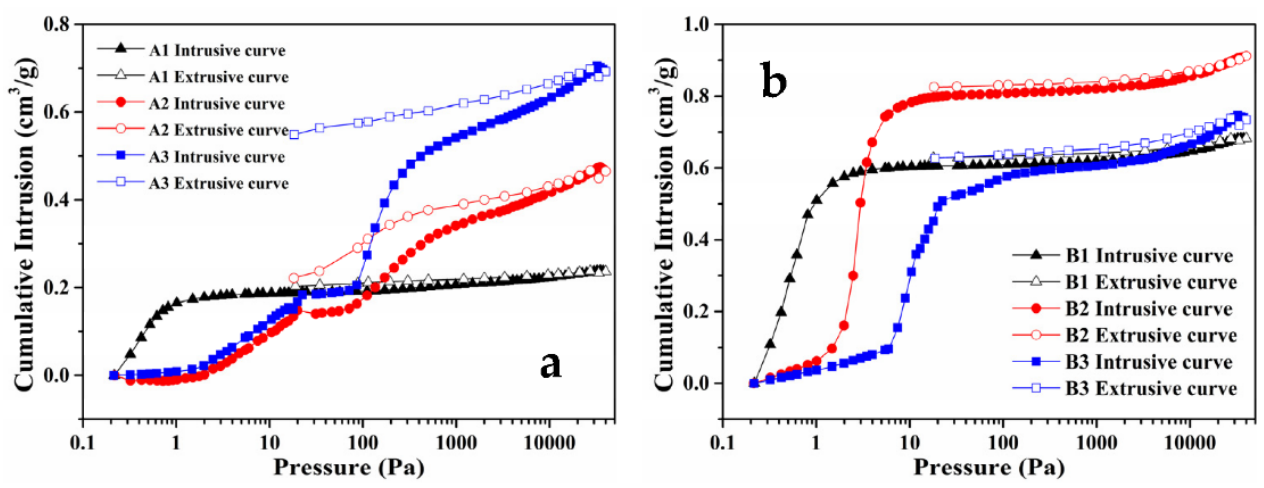

Figure 1. MIP intrusive and extrusive curves of the mudstone (a) and coal (b) samples under different granule diameter conditions.

Additionally, the hysteresis loop of MIP profiles is a handy tool to evaluate the pore network structure and connectivity of porous medium [28,30]. In general, the MIP profiles of open pores and chokepoint holes (such as the inkstand hole) have hysteresis loops because the mercury ejection pressure was not equal to the mercury injection pressure [32]. As shown in Figure 1a,b, with the granule diameter decreased, the hysteresis loops of both mudstone and coal became more pronounced, suggesting that the proportion of open holes in mudstone and coal increased, and the holes became preferably contacted with each other. Furthermore, the changing trend of the hysteresis loop in mudstone was more apparent, indicating that the crushing process had a more significant impact on mudstone. According to the previous study, the change of pore characteristic for coal in the smashing process verified that it was beneficial to the methane storage and migration in coal $[32,33]$.

The pore structural parameters of mudstone and coal specimens with distinct granule diameters from the MIP measurement are summarized in Table 1 . In order to accurately and comprehensively describe the pore structure characteristics, the only pore data above $50 \mathrm{~nm}$ from the MIP measurement were analyzed. The total pore areas of A1, A2, A3, B1, B2, and B3 specimens were $7.14,26.78,32.10,18.75,23.60$, and $33.31 \mathrm{~m}^{2} / \mathrm{g}$, respectively, which indicated that the total pore areas of mudstone and coal samples all gradually increased as the particle sizes decreased. Moreover, the macropore pore areas of both mudstone and coal also displayed the same variation rules. As shown in Figure 2a,b, with the decreasing of granule diameters, the contribution of the mesopore and macropore of both mudstone and coal to the pore areas gradually increased. The porosities of both mudstone and coal also progressively increased as the granule diameters reduced, and the A3 ( $>200$ mesh) and B3 (>200 mesh) have the highest porosities, and they were respectively $61.24 \%$ and $63.05 \%$. These analyses all suggested that some closed holes in mudstone and coal were converted to semi-enclosed or open holes during the crushing process. Moreover, some long pores became short pores, or some crosslinked holes were potentially separated into different segments because of their smaller particle sizes [28,34].

Table 1. Pore structural parameters of mudstone and coal specimens with distinct granule diameters from the MIP measurement.

\begin{tabular}{ccccccc}
\hline Samples & A1 & A2 & A3 & B1 & B2 & B3 \\
\hline Total pore area $\left(\mathrm{m}^{2} / \mathrm{g}\right)$ & 7.14 & 26.78 & 32.10 & 18.75 & 23.60 & 33.31 \\
Micropore pore areas $\left(\mathrm{m}^{2} / \mathrm{g}\right)$ & 0 & 0 & 0 & 0 & 0 & 0 \\
Mesopore pore areas $\left(\mathrm{m}^{2} / \mathrm{g}\right)$ & 6.64 & 23.92 & 28.26 & 18.11 & 22.84 & 31.93 \\
Macropore pore areas $\left(\mathrm{m}^{2} / \mathrm{g}\right)$ & 0.50 & 2.86 & 3.84 & 0.64 & 0.76 & 1.38 \\
Total pore volume $\left(\mathrm{cm}^{3} / \mathrm{g}\right)$ & 0.24 & 0.47 & 0.69 & 0.68 & 0.90 & 0.73 \\
Micropore volume $\left(\mathrm{cm}^{3} / \mathrm{g}\right)$ & 0 & 0 & 0 & 0 & 0 & 0 \\
Mesopore volume $\left(\mathrm{cm}^{3} / \mathrm{g}\right)$ & 0.03 & 0.09 & 0.10 & 0.05 & 0.07 & 0.10 \\
Macropore volume $\left(\mathrm{cm}^{3} / \mathrm{g}\right)$ & 0.21 & 0.38 & 0.59 & 0.63 & 0.83 & 0.63 \\
Porosity $(\%)$ & $38.61 \%$ & $59.89 \%$ & $61.24 \%$ & $47.08 \%$ & $51.98 \%$ & $63.05 \%$ \\
\hline
\end{tabular}



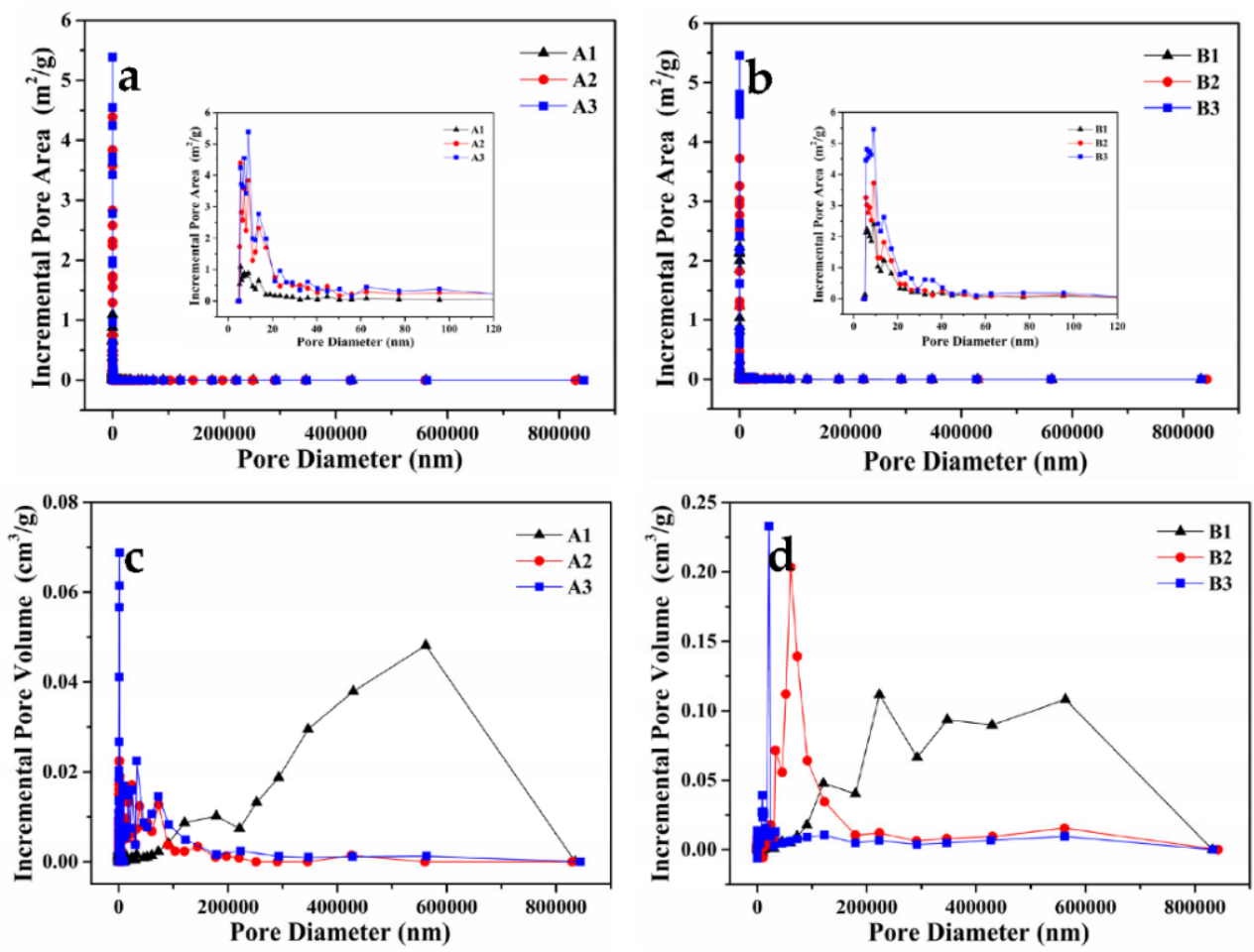

Figure 2. Curves of incremental pore area vs. pore diameter of the mudstone (a) and coal (b) specimens with distinct granule diameters, and the inserts were the partial enlargement curves, the curves of incremental pore volume vs. pore diameter of the mudstone (c) and coal (d) specimens with distinct granule diameters.

As shown in Table 1, with the reducing granule diameter, the total pore and macropore volumes of mudstone all increased continually. In contrast, the total pore and macropore volumes of coal increased first and then decreased. This finding might be down to the fact that partial macropores of the coal sample with a particle size bigger than 200 mesh were destroyed. The curves of incremental pore volume vs. pore diameter of the mudstone and coal specimens with distinct granule diameters are exhibited in Figure $2 \mathrm{c}$, d. We can conclude that the contribution of the smaller holes to the pore volume gradually increased for both mudstone and coal as the granule diameter reduced. Figure 3 exhibits the pore-sizedistribution profiles of the mudstone and coal specimens with distinct granule diameters from the MIP measurement. With respect to A1, the A2 and A3 samples displayed similar pore-size-distribution curves, except for the number of pores. However, for coal, it was observed that the prominent peaks of pore-size-distribution curves gradually moved to the left, indicating the increase of smaller pores. These findings indicated that the crushing process only had a significant impact on the pore feature of mudstone with the granule diameter of less than 100 mesh, while the crushing process still could alter the pore feature of coal with granule diameter of greater than 100 mesh. 

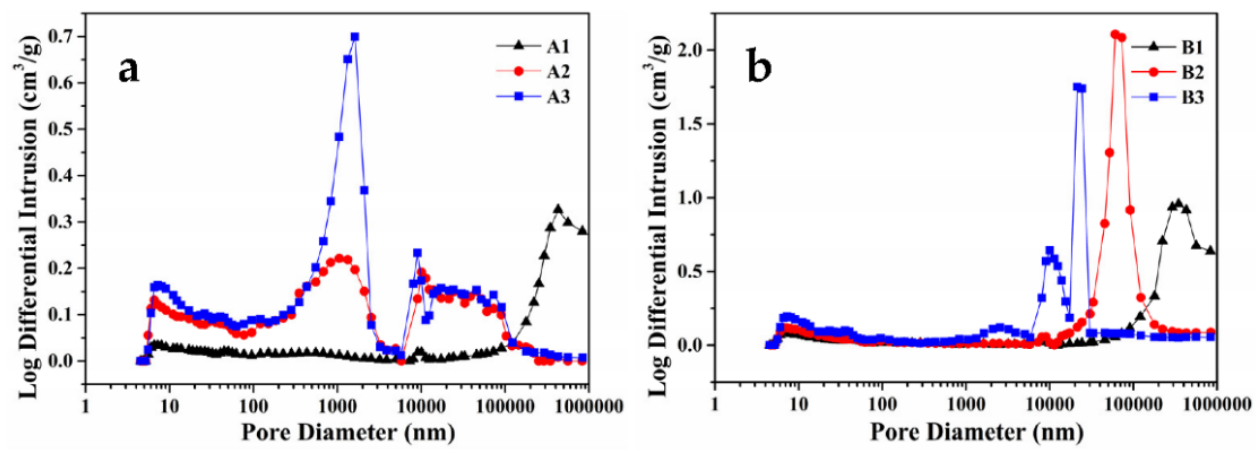

Figure 3. Pore-size-distribution profiles of the mudstone (a) and coal (b) specimens with distinct granule diameters from the MIP measurement.

\subsection{The $L T-N_{2} A$ Measurement}

The LT- $\mathrm{N}_{2} \mathrm{~A}$ isotherms of the mudstone and coal specimens with distinct granule diameters are shown in Figure 4. According to the IUPAC criteria, the adsorption isotherms of porous materials can be divided into eight categories, and the resulting hysteresis cycles have five sorts $[28,35]$. We can see that the isotherms of all specimens with different granule diameters in this paper presented similar shapes and could be categorized as an integration of type IV/II isotherms. The adsorption process of the mudstone and coal samples had, in sequence, undergone the micropore filling, multimolecular layer adsorption, multimolecular layer adsorption, capillary condensation in the mesopores, and the ultimate saturation platform [36]. The $\mathrm{N}_{2}$ adsorbed quantities of the mudstone samples A1 (20-40 mesh), A2 (80-100 mesh), and A3 (>200 mesh) were 9.96, 26.25, and $26.19 \mathrm{~cm}^{3} / \mathrm{g}$, respectively, which showed a law of increasing first and then almost unchanged as the granule diameter decreased. However, the $\mathrm{N}_{2}$ adsorbed quantities of the coal samples B1 (20-40 mesh), B2 (80-100 mesh), and B3 (>200 mesh) were 1.45, 1.59, and $3.81 \mathrm{~cm}^{3} / \mathrm{g}$, respectively, and they displayed a law of increasing gradually as the granule diameter decreased. This phenomenon further showed that the crushing process could alter the pore structure of coal with granule diameter of larger than 100 mesh, but not for mudstone. Furthermore, the shape of hysteresis loops for all samples could be classified as Type $\mathrm{H} 4$, indicating that these mudstones and coals samples were non-rigid aggregates with micropores, plate-shaped pores, and slit-shaped pores developed inside [37]. As the granule diameter decreased, the hysteresis loops' shapes for all samples was hardly unchanged, suggesting that the crushing procedure had little effect on the hole shape [26].
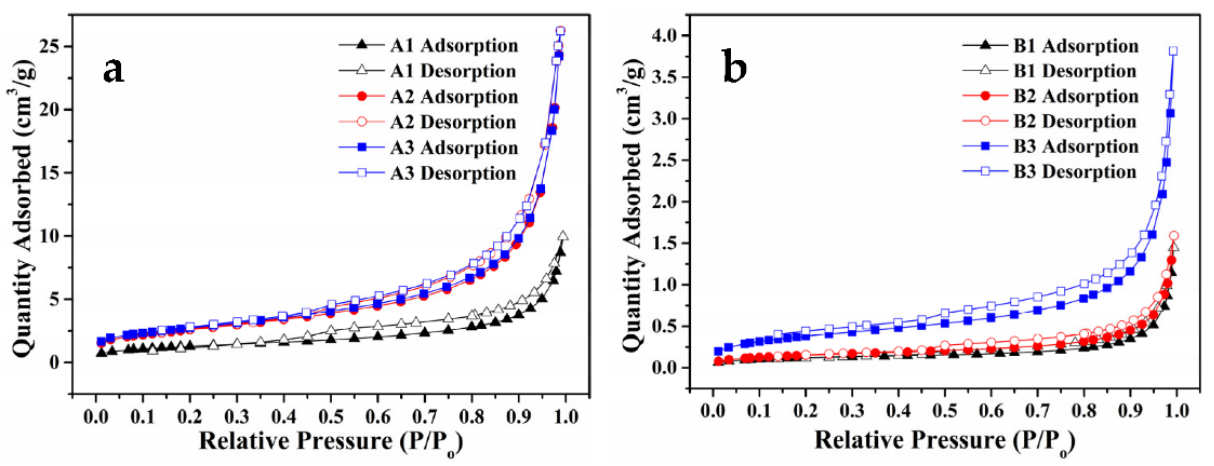

Figure 4. LT- $\mathrm{N}_{2} \mathrm{~A}$ isotherms of the mudstone (a) and coal (b) specimens with distinct granule diameters.

The $\mathrm{BJH}$ pore structural parameters of the mudstone and coal specimens with distinct granule diameters from the LT- $\mathrm{N}_{2} \mathrm{~A}$ measurement are shown in Table 2. To increase the precision rate of the analysis, the pore-structure data below $50 \mathrm{~nm}$ from the LT- $\mathrm{N}_{2} \mathrm{~A}$ measurement were used. As shown in Table 2, we can see that the total and mesopore 
specific surface areas of the mudstone and coal specimens all increased gradually with the decreasing of granule diameters. Moreover, the mesopore volumes of the mudstone samples A1, A2, and A3 were respectively $0.00755,0.01884$, and $0.01984 \mathrm{~cm}^{3} / \mathrm{g}$, and the mesopore volumes of the coal samples B1, B2, and B3 were respectively $0.00058,0.00088$, and $0.00224 \mathrm{~cm}^{3} / \mathrm{g}$, which all showed a tendency of increasing continually. These results strongly demonstrated that decreasing the granule diameters led to a successive increase in mesopore-specific surface areas and volumes for both the mudstone and coal specimens.

Table 2. BJH pore structural parameters of the mudstone and coal specimens with distinct granule diameters from the LT- $\mathrm{N}_{2} \mathrm{~A}$ measurement.

\begin{tabular}{ccccccc}
\hline Samples & A1 & A2 & A3 & B1 & B2 & B3 \\
\hline Total specific surface area $\left(\mathrm{m}^{2} / \mathrm{g}\right)$ & 4.63 & 10.37 & 10.52 & 0.38 & 0.54 & 1.46 \\
Micropore specific surface area $\left(\mathrm{m}^{2} / \mathrm{g}\right)$ & 0.29 & 0.35 & 0.34 & 0.05 & 0.04 & 0.14 \\
Mesopore specific surface area $\left(\mathrm{m}^{2} / \mathrm{g}\right)$ & 3.94 & 8.7 & 8.92 & 0.261 & 0.428 & 1.14 \\
Macropore specific surface area $\left(\mathrm{m}^{2} / \mathrm{g}\right)$ & 0.40 & 1.32 & 1.26 & 0.069 & 0.072 & 0.18 \\
Total pore volume $\left(\mathrm{cm}^{3} / \mathrm{g}\right)$ & 0.016 & 0.041 & 0.042 & 0.0022 & 0.0025 & 0.0060 \\
Micropore volume $\left(\mathrm{cm}^{3} / \mathrm{g}\right)$ & 0.00015 & 0.00016 & 0.00016 & 0.00002 & 0.00002 & 0.00006 \\
Mesopore volume $\left(\mathrm{cm}^{3} / \mathrm{g}\right)$ & 0.00755 & 0.01884 & 0.01984 & 0.00058 & 0.00088 & 0.00224 \\
Macropore volume $\left(\mathrm{cm}^{3} / \mathrm{g}\right)$ & 0.0083 & 0.022 & 0.022 & 0.0016 & 0.0016 & 0.0037 \\
\hline
\end{tabular}

The micropore specific surface areas of the mudstone with granule diameters of 20-40 mesh (A1), 80-100 mesh (A2), and >200 mesh (A3) were $0.29,0.35$, and $0.34 \mathrm{~cm}^{3} / \mathrm{g}$, respectively, which first increased and then decreased. The micropore specific surface areas of the coal with granule diameters of 20-40 mesh (B1), 80-100 mesh (B2), and >200 mesh (B3) were $0.05,0.04$, and $0.14 \mathrm{~cm}^{3} / \mathrm{g}$, respectively, which decreased first, followed by an increase. However, the micropore volumes of both the mudstone and coal samples showed little change as the particle size changed, thus indicating that the crushing procedure almost did not influence the micropore characteristics of the mudstone and coal. Besides, combined with the analyses of the MIP measurement on the macropore and the LT- $\mathrm{N}_{2} \mathrm{~A}$ measurement on the mesopore, we can conclude that the effect of the crushing process on the mesopore was the most significant, followed by the macropore, and on the micropore, it was negligible for both the mudstone and coal samples.

The pore-size-distribution curves of the mudstone and coal specimens with distinct granule diameters from the LT- $\mathrm{N}_{2} \mathrm{~A}$ measurement are exhibited in Figure 5. For the mudstone specimens, as the granule diameters decreased, the proportion of mesopores increased, and that of micropores decreased. However, the A2 and A3 specimens showed very similar pore-size-distribution profiles. For the coal specimens, the proportions of mesopores and micropores all increased with the decreasing of the granule diameters. The above results indicated that the crushing process could modify the pore structure characteristics of coal with granule diameter of larger than 100 mesh, but not apparent for mudstone with the same particle size, which gave very good agreement the results of Figures 3 and 4 .
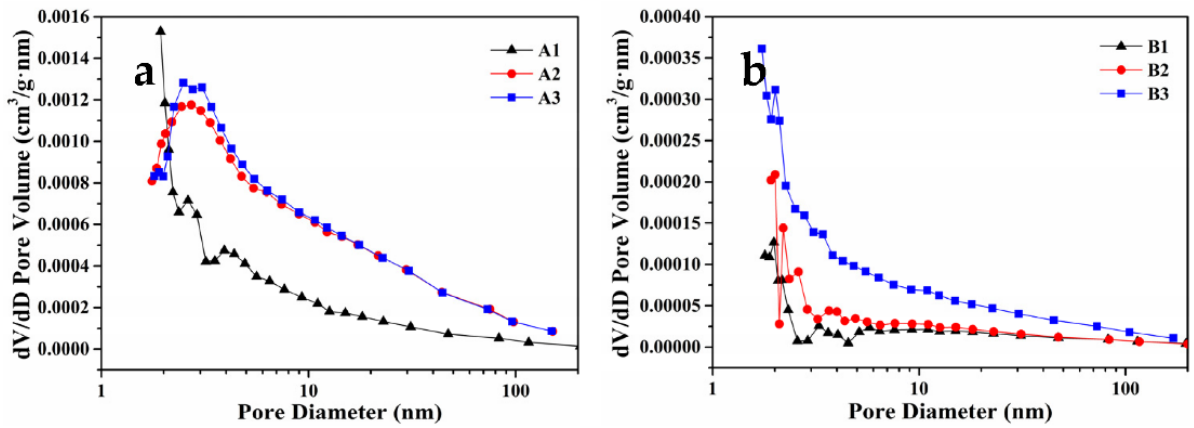

Figure 5. Pore-size-distribution curves of the mudstone (a) and coal (b) specimens with distinct granule diameters from the LT- $\mathrm{N}_{2} \mathrm{~A}$ measurement. 


\section{Conclusions}

In summary, the mudstone and coal samples collected from the Pingdingshan coal mine were smashed and sieved into three distinct granule diameters. A series of the MIP and LT- $\mathrm{N}_{2} \mathrm{~A}$ measurements were conducted to probe the influence of the granule diameters on the pore structure characteristics of mudstone and coal. The conclusions are as follows: (1) The MIP tests revealed that, as the particle sizes decreased, the mercury withdrawal efficiency decreased, whereas the porosities increased gradually, and the hysteresis loops became more evident for both mudstone and coal, indicating that the proportion of open pores or semi-enclosed pores increased and the pores became preferable contacted each other during the crushing process. The change in the coal pore structure in the smashing process was beneficial to methane storage and migration. (2) The LT- $\mathrm{N}_{2} \mathrm{~A}$ measurements revealed that, with the decreasing of the granule diameters, the total specific surface areas and pore volumes all showed a tendency of increasing continually for both mudstone and coal. The shape of hysteresis loops indicated that mudstone and coal were non-rigid aggregates with micropores, plate-shaped pores and slit-shaped pores developed inside, and the crushing procedure has little effect on the pore shape. (3) The effect of the particle sizes on the mesopore was the most significant, followed by the macropore, and on the micropore, it was negligible for both mudstone and coal. The crushing process could modify the pore structure characteristics of coal with a granule diameter of larger than 100 mesh, but not apparent for mudstone with the same particle size.

Author Contributions: Conceptualization, J.Z. and X.L.; methodology, J.L. and F.C.; validation, J.Z., X.L. and J.J.; data curation, J.L. and F.C.; writing—original draft preparation, J.Z.; writing-review and editing, F.C. and Z.S.; supervision, Z.S.; funding acquisition, J.L., F.C. and Z.S. All authors have read and agreed to the published version of the manuscript.

Funding: This research was funded by the National Natural Science Foundation of China, grant numbers 41872169, 41972177, and 42172189; the Scientific Research Cultivation Fund Project of Henan University of Engineering, grant number PYXM202105; the Key Scientific Research Projects of Henan Colleges and Universities, grant numbers 20A170006 and 21A610002; the Postdoctoral Science Foundation China, grant number 2018M642747; and the National Natural Science Foundation of Henan province, grant number 202300410099.

Institutional Review Board Statement: Not applicable.

Informed Consent Statement: Not applicable.

Data Availability Statement: Not applicable.

Acknowledgments: The authors would like to thank the workers in Shiyanjia Lab (www.shiyanjia. com) for the testing service.

Conflicts of Interest: The authors declare no conflict of interest.

\section{References}

1. Wang, L.; Chen, Z.; Wang, C.; Elsworth, D.; Liu, W. Reassessment of coal permeability evolution using steady-state flow methods: The role of flow regime transition. Int. J. Coal Geol. 2019, 211, 103210. [CrossRef]

2. Wang, G.; Han, D.; Jiang, C.; Zhang, Z. Seepage characteristics of fracture and dead-end pore structure in coal at micro- and meso-scales. Fuel 2020, 266, 117058. [CrossRef]

3. Tang, X.; Ripepi, N.; Luxbacher, K.; Pitcher, E. Adsorption models for methane in shales: Review, comparison, and application. Energy Fuels 2017, 31, 10787-10801. [CrossRef]

4. Song, Y.; Jiang, B.; Li, M.; Hou, C.; Xu, S. A review on pore-fractures in tectonically deformed coals. Fuel 2020, 278, 118248. [CrossRef]

5. Nie, B.; Liu, X.; Yang, L.; Meng, J.; Li, X. Pore structure characterization of different rank coals using gas adsorption and scanning electron microscopy. Fuel 2015, 158, 908-917. [CrossRef]

6. He, X.; Liu, X.; Nie, B.; Song, D. FTIR and Raman spectroscopy characterization of functional groups in various rank coals. Fuel 2017, 206, 555-563. [CrossRef]

7. Xun, M.; Xie, J.; Xie, J.; Sun, Q.; Lu, S.; Wang, G. Study on the effect of acid-heat coupling on the damage characteristics of coal pore-fissure structure. Adv. Powder Technol. 2021, 32, 3425-3435. [CrossRef] 
8. Hou, S.; Wang, X.; Wang, X.; Yuan, Y.; Pan, S.; Wang, X. Pore structure characterization of low volatile bituminous coals with different particle size and tectonic deformation using low pressure gas adsorption. Int. J. Coal Geol. 2017, 183, 1-13. [CrossRef]

9. Liu, S.; Sang, S.; Pan, Z.; Tian, Z.; Yang, H.; Hu, Q.; Sang, G.; Qiao, M.; Liu, H.; Jia, J. Study of characteristics and formation stages of macroscopic natural fractures in coal seam \#3 for CBM development in the east Qinnan block, Southern Quishui Basin, China. J. Nat. Gas Sci. Eng. 2016, 34, 1321-1332. [CrossRef]

10. Liu, S.-Q.; Sang, S.-X.; Liu, H.-H.; Zhu, Q.-P. Growth characteristics and genetic types of pores and fractures in a high-rank coal reservoir of the southern Qinshui basin. Ore Geol. Rev. 2015, 64, 140-151. [CrossRef]

11. Chen, Y.; Qin, Y.; Wei, C.; Huang, L.; Shi, Q.; Wu, C.; Zhang, X. Porosity changes in progressively pulverized anthracite subsamples: Implications for the study of closed pore distribution in coals. Fuel 2018, 225, 612-622. [CrossRef]

12. Li, T.; Wu, J.J.; Wang, X.G.; Huang, H. Particle size effect and temperature effect on the pore structure of low-rank coal. ACS Omega 2021, 6, 5865-5877. [CrossRef]

13. Pan, J.; Wang, S.; Ju, Y.; Hou, Q.; Niu, Q.; Wang, K.; Li, M.; Shi, X. Quantitative study of the macromolecular structures of tectonically deformed coal using high-resolution transmission electron microscopy. J. Nat. Gas Sci. Eng. 2015, 27, 1852-1862. [CrossRef]

14. Rugar, D.; Hansma, P. Atomic force microscopy. Phys. Today 1990, 43, 23-30. [CrossRef]

15. Fang, H.; Sang, S.; Liu, S.; Du, Y. Methodology of three-dimensional visualization and quantitative characterization of nanopores in coal by using FIB-SEM and its application with anthracite in Qinshui basin. J. Petrol. Sci. Eng. 2019, 182, 106285. [CrossRef]

16. Wang, Z.; Zhou, H.; Li, Y.; Zhang, P.; Mao, R.; Ren, L.; Luo, J. Experimental study of the pore structure during coal and biomass ash sintering based on X-ray CT technology. Energy Fuels 2021, 35, 2098-2109. [CrossRef]

17. Andrésen, J.M.; Martín, Y.; Moinelo, S.R.; Maroto-Valer, M.M.; Snape, C.E. Solid state ${ }^{13}$ C NMR and high temperature ${ }^{1} \mathrm{H}$ NMR determination of bulk structural properties for mesophase-containing semi-cokes prepared from coal tar pitch. Carbon 1998, 36, 1043-1050. [CrossRef]

18. Maroto-Valerlya, M.M.; Taulbee, D.N.; Andrésen, J.M.; Hower, J.C.; Snape, C.E. Quantitative ${ }^{13}$ C NMR study of structural variations within the vitrinite and inertinite maceral groups for a semifusinite-rich bituminous coal. Fuel 1998, 77, 805-813. [CrossRef]

19. Clarkson, C.R.; Solano, N.; Bustin, R.M.; Bustin, A.M.M.; Chalmers, G.R.L.; He, L.; Melnichenko, Y.B.; Radliński, A.P.; Blach, T.P. Pore structure characterization of North American shale gas reservoirs using USANS/SANS, gas adsorption, and mercury intrusion. Fuel 2013, 103, 606-616. [CrossRef]

20. Sakurovs, R.; He, L.; Melnichenko, Y.B.; Radlinski, A.P.; Blach, T.; Lemmel, H.; Mildner, D.F.R. Pore size distribution and accessible pore size distribution in bituminous coals. Int. J. Coal Geol. 2012, 100, 51-64. [CrossRef]

21. Bale, H.D.; Schmidt, P.W. Small-angle X-ray-scattering investigation of submicroscopic porosity with fractal properties. Phys. Rev. Lett. 1984, 53, 596-599. [CrossRef]

22. Okolo, G.N.; Everson, R.C.; Neomagus, H.W.J.P.; Roberts, M.J.; Sakurovs, R. Comparing the porosity and surface areas of coal as measured by gas adsorption, mercury intrusion and SAXS techniques. Fuel 2015, 141, 293-304. [CrossRef]

23. Jiang, J.; Yang, W.; Cheng, Y.; Zhao, K.; Zheng, S. Pore structure characterization of coal particles via MIP, $\mathrm{N}_{2}$ and $\mathrm{CO}_{2}$ adsorption: Effect of coalification on nanopores evolution. Powder Technol. 2019, 354, 136-148. [CrossRef]

24. Zhang, M.; Duan, C.; Li, G.; Fu, X.; Zhong, Q.; Liu, H.; Dong, Z. Determinations of the multifractal characteristics of the pore structures of low-, middle-, and high-rank coal using high-pressure mercury injection. J. Pet. Sci. Eng. 2021, $203,108656$. [CrossRef]

25. Mastalerz, M.; Drobniak, A.; Strapoć, D.; Acosta, W.S.; Rupp, J. Variations in pore characteristics in high volatile bituminous coals: Implications for coal bed gas content. Int. J. Coal Geol. 2008, 76, 205-216. [CrossRef]

26. Yi, M.; Cheng, Y.; Wang, Z.; Wang, C.; Hu, B.; He, X. Effect of particle size and adsorption equilibrium time on pore structure characterization in low pressure $\mathrm{N}_{2}$ adsorption of coal: An experimental study. Adv. Powder Technol. 2020, 31, 4275-4281. [CrossRef]

27. Hodot, B.B. Coal and Gas Outburst; Chemical Industry Press: Beijing, China, 1966.

28. Guo, H.; Yuan, L.; Cheng, Y.; Wang, K.; Xu, C. Experimental investigation on coal pore and fracture characteristics based on fractal theory. Powder Technol. 2019, 346, 341-349. [CrossRef]

29. Niu, X.; Han, Y.; Feng, G.; Cui, J. Effect of the physicochemical structure of mudstone on readsorption behavior of water. Energy Fuels 2020, 35, 386-396. [CrossRef]

30. Liu, J.; Ma, J.; Jiang, X.; Jiang, X. The multi-scale pore structure of superfine pulverized coal. Part 1. Macropore morphology. Fuel 2021, 304, 120728. [CrossRef]

31. Giesche, H. Mercury porosimetry: A general (practical) overview. Part. Part. Syst. Charact. 2006, 23, 9-19. [CrossRef]

32. Chen, S.; Zhu, Y.; Li, W.; Wang, H. Influence of magma intrusion on gas outburst in a low rank coal mine. Int. J. Min. Sci. Technol. 2012, 22, 259-266. [CrossRef]

33. Cai, Y.; Liu, D.; Pan, Z.; Yao, Y.; Li, J.; Qiu, Y. Pore structure and its impact on $\mathrm{CH}_{4}$ adsorption capacity and flow capability of bituminous and subbituminous coals from Northeast China. Fuel 2013, 103, 258-268. [CrossRef]

34. Guo, H.; Cheng, Y.; Ren, T.; Wang, L.; Yuan, L.; Jiang, H.; Liu, H. Pulverization characteristics of coal from a strong outburst-prone coal seam and their impact on gas desorption and diffusion properties. J. Nat. Gas. Sci. Eng. 2016, 33, 867-878. [CrossRef] 
35. Rouquerol, J.; Avnir, D.; Fairbridge, C.W.; Everett, D.H.; Haynes, J.H.; Pernicone, N.; Ramsay, J.D.F.; Sing, K.S.W.; Unger, K.K. Recommendations for the characterization of porous solids. Pure Appl. Chem. 1994, 66, 1739-1758. [CrossRef]

36. Jin, K.; Cheng, Y.; Liu, Q.; Zhao, W.; Wang, L.; Wang, F.; Wu, D. Experimental investigation of pore structure damage in pulverized coal: Implications for methane adsorption and diffusion characteristics. Energy Fuels 2016, 30, 10383-10395. [CrossRef]

37. Yu, S.; Bo, J.; Liu, J.G. Nanopore structural characteristics and their impact on methane adsorption and diffusion in low to medium tectonically deformed coals: Case study in the Huaibei coal field. Energy Fuels 2017, 31, 6711-6723. [CrossRef] 